\title{
Local, regional and global patterns of resource use in ecology: hermit crabs and gastropod shells as an example
}

\author{
David K. A. Barnes ${ }^{1,2,3, *}$ \\ ${ }^{1}$ Department of Zoology and Animal Ecology, University College Cork, Lee Maltings, Cork, Ireland \\ ${ }^{2}$ FRONTIER, 52 Rivington street, London EC2A 4QS, United Kingdom \\ ${ }^{3}$ Present address: British Antarctic Survey, High Cross, Madingley Road, Cambridge CB3 0ET, United Kingdom
}

\begin{abstract}
To see the 'big pictures', it seems increasingly clear that experimental design, data collection and analyses of ecological investigation need to be at multiple scales. This causes problems with data complexity, sampling (level) and independence. Many ecological programmes are currently conducting multi-scale investigation of organismal trends (e.g. diversity). In this study, by contrast, the assemblages analysed were the resources used by animals (rather than animals per se). Variability in shell use was studied in 5 members of a taxon (hermit crabs) from global to site spatial levels. The novel adaptation of an existing technique used 1-factor, 3-level ANOVA of Bray-Curtis similarity values based on 'centroids' for each scale. Similarity in the number of shells used, the proportional usage of shell types, shell diversity and other variables were examined at site ( $>10 \mathrm{~m}$ apart), locality ( $>1 \mathrm{~km}$ apart) and region levels (>1000 km apart). There was significant variability amongst scales and between regions in shell use of all species. For some species, observed variability differed with location, while in others the trend was similar in all 3 regions. Between 18 and 3 shell types were used by different study species with diversity (Shannon $H^{\prime}$ ) values ranging from 2.54 to 0.1 and evenness values from 0.99 to 0.1 . Shell use by hermit crabs was less similar (to each other) between regions than between the study hermit crab species. No significant spatial effects at any level were found on the proportion of damaged shells used by different species. The numbers of shell types used by hermit crabs had both a taxon-specific component and a global pattern. Data from the literature in combination with that from the present study showed Dardanus, Diogenes and Pagurus species used fewer shell types than Coenobita, Clibanarius and Calcinus species. No inter-oceanic patterns were evident in any genus. Shell numbers used by Clibanarius and Calcinus species both, however, exhibited distinct latitudinal clines. Adaptation of a novel technique has, thus, demonstrated global (and differential between scale) trends in resource use by a guild of animals, although interpretation of the mechanism or meaning underlying this is not straightforward.
\end{abstract}

KEY WORDS: Hermit crab $\cdot$ Intertidal $\cdot$ Resource use $\cdot$ Shells $\cdot$ Scale $\cdot$ West Indian Ocean

\section{INTRODUCTION}

Attempts at deciphering wide-scale trends in ecology have often focussed on number of taxa, range of taxa or particular physiological traits such as reproductive patterns or larval strategies (Thorson's rule, see Mileikovsky 1971). Among marine fauna, molluscs are often the group in which large-scale trends and patterns are studied, e.g. Thorson's rule, shell morphology and diversity. Variability in mollusc shell features was one of the first pieces of evidence used to illustrate modern inter-oceanic faunistic variability (Vermeij 1976). More recently, Roy et al. (1998) found evidence of a real latitudinal diversity cline by investigating gastropod species richness in the Americas. The causes of such trends have been even more diffi- 
cult to elucidate and more controversial than the trends themselves (Gray 2001). Differences in major ecological factors such as ecosystem age, tectonic history, sea level fluctuation and predation may be responsible for architectural variability (Vermeij 1976, Briggs 1987). Primary productivity regimes driven by solar input were considered to be the primary cause of a gastropod diversity cline (Roy et al. 1998), while ecosystem age is argued to be more important in explaining bivalve patterns (Crame 2000). Trends in gastropod molluscs are extremely important to the study reported here, as they determined the pattern of resource providers.

Molluscs are among the few bio-constructors of nonattached skeletal material which can be actively used by other organisms. Some such organisms simply use the shell as hard substratum for incrustation, others facultatively use it as a refugial burrow (such as sipunculan worms), while others, the hermit crabs, are obligate users to prevent mechanical damage to unhardened abdominal regions. Hermit crab species often have quite specific resource requirements and preferences (architecture, mass or strength), in relation to which they have evolved ritualised behaviour patterns (Reese 1969). The shells utilised by hermit crabs, however, actually have more to do with local availability than any other factor (Leite et al. 1998, Barnes 1999). Thus, while large-scale patterns are undoubtedly important, processes can operate (and change) across a wide variety of scales (Underwood \& Chapman 1996, 1998). Understanding patterns of variability will require appreciation of 'all size pictures' as well as the 'big one'. Perhaps what may be most useful to an overview of variability is simultaneous analyses at multiple scales designed to include the potential of interaction between scales. Until recently, there have been a number of problems associated with analysing patterns of variability in assemblages (such as species richness) at several scales in a given parameter, such as space (as a dimension of scale). The first problem has been one of sampling strategy linked to the requirements of powerful multi-variate statistical procedures, such as ANOVA. Without very large-scale sampling programmes, re-use of sample units is needed to compare data sets at multiple scales which, therefore, makes sample units at different scales nonindependent. Problems of non-independence can be avoided by rank order techniques, but these do not produce quantitative comparable measures of similarity (or dissimilarity). Underwood \& Chapman (1998) describe a novel method using average assemblages of samples, which they term 'centroids'. A centroid, in the context of this study, is an assemblage of average composition. Therefore, at the lowest spatial scale, this is formed by the mean of site samples (which were quadrats in the present study). At each level, the centroids may be averaged to produce centroids for the next level. The level of similarity between centroids of each scale and independent replicate samples at each scale can then be compared. The only sampling requirement is that enough random samples are taken at the lowest (spatial) scale to provide enough replicates to compare with centroids such that replicates are not re-used. Although their method was suggested for whole assemblages, it could theoretically be used for a feature of assemblages. This novel study applies the method to investigate variability in resource use (mollusc shells) by hermit crabs at 3 spatial scales, the largest being a region in the West Indian Ocean.

Throughout the tropics and subtropics, hermit crabs are locally abundant, speciose and occupy a high proportion of the total gastropod shells present (Lewinsohn 1982, Reay \& Haig 1990, Gherardi \& McLaughlin 1994, Hogarth et al. 1998). Both Mozambique and Madagascar have particularly high numbers of hermit crabs (Hilgendorf 1878, Table 1 in Reay \& Haig 1990) and molluscs (see Mars et al. 1972, Barnes et al. 1998). Humans are major harvesters of gastropod shells, particularly in this region; empty shells are deposited in piles or middens on the shore after removal of edible material. This practice increases shell supply in an otherwise somewhat resource restricted situation for hermit crabs and strengthens preference patterns (Barnes \& De Grave 2000). The combination of site remoteness, hermit crab and gastropod resource abundance and lack of previous study make the regions highly appropriate for both study on a local scale and 'filling in' a knowledge gap on a global scale.

This nested multi-scale study of West Indian Ocean hermit crabs aimed to address whether hermit crab species identity or locality was of more importance for the selection of shell types and characteristics. In addition, the study asked on what spatial scale does shell utilisation vary most and how is such variability expressed (in numerical magnitude of utilised shells, types of shell used or proportional use of specific shell types). More specifically it was hypothesised that: (1) between region variability would be greater than between locality and that variability in both would be greater than at site level; (2) between hermit crab species variability would be greater than spatial levels of variability; (3) patterns of variability would differ between the type of parameter chosen (shell diversity, shell number etc.); and (4) established global patterns in the literature for the resource (more Indo-Pacific gatropod species than Atlantic: Vermeij 1976; decreasing gastropod species numbers with increasing latitude: Roy et al. 1998) are reflected in the resource use by hermit crabs. 


\section{MATERIALS AND METHODS}

Study area and species. The variability of resources (gastropod shells) used by hermit crabs was studied in 3 regions (>1000 km apart); northern Mozambique (Quirimba Archipelago), SW Madagascar (Anakao) and southern Mozambique (Inhaca Island). Within the regions, resource variability was studied at 3 localities ( $>1 \mathrm{~km}$ apart) and within each locality at 15 sites (>10 $\mathrm{m}$ apart). The mean and range of distances between sites was $24.4 \mathrm{~m}$ and 14 to $33 \mathrm{~m}$, respectively. The study localities were Quisiva Island, Mefunvo Island and Quirimba Island in N Mozambique; Andavoka, Nosy Satrana and Nosy Ve in SW Madagascar, and NW, W and SW Inhaca Island in S Mozambique. Five hermit crab species, Coenobita rugosus, Clibanarius longitarsus, Clibanarius virescens, Calcinus laevimanus and Calcinus latens were abundant in all 3 regions and the resource use of these species only were recorded. Additional observations are made on a sixth species, Diogenes gardinieri, present in all regions. The mobility of 2 of the study species (Coenobita rugosus and Clibanarius longitarsus) were such that distances between sites could be covered within a tidal cycle. The sites were, nevertheless, independent of each other as the timing of sampling was during the period of minimal hermit crab movement $(<1 \mathrm{~m}$ observed in any study species), day low tides.

Conspecifics and heterospecifics were a potential source of shells, but empty shells were common and hermit crabs in all 3 study regions were not shell restricted (Barnes 1999, 2001). Hypotheses (1), (2) and (3) were testable with the original data collected in this study. The final hypothesis, that examining global trends, required data from the literature by its very nature.

Protocol. The species (= type), and the number and percentage of each type of gastropod shell inhabited was recorded for each study hermit crab species selected from within 15 randomly placed $4 \mathrm{~m}^{2}$ quadrats (each quadrat represents a site). The 2 Coenobita species were sampled between mean high water neap (MHWN) level and $10 \mathrm{~m}$ inland from this. Clibanarius longitarsus was sampled between MHWN and mean high water spring (MHWS) levels. The remaining hermit crab species were sampled between mean low water spring (MLWS) and mean tide levels. Sampling was carried out during diurnal low water periods when all of the study hermit crabs species formed clusters (to varying degrees). Shells were recorded as damaged if parts of the whorls were missing. The number of types of living and empty molluscs was also recorded within all sample sites for each region. Diversity and evenness of shell types used was investigated using the Shannon-Wiener diversity index, and similarity analysed and compared using Bray-Curtis modified Sorensen
(Dice) coefficient (Wolda 1981). This is a cluster analysis measure for abundance data using the formula:

$$
\text { BrayCurtis }_{j k}=\frac{\sum_{i=1}^{3}\left|\chi_{i j}-\chi_{i k}\right|}{\sum_{i=1}^{3}\left(\chi_{i j}+\chi_{i k}\right)}
$$

Following the protocol of Underwood \& Chapman (1998), the Bray-Curtis similarity values from all 15 sites (quadrats) were averaged to give a 'centroid' of the resource assemblage for each locality (giving an average value for all individual shell types). The data from 5 randomly chosen sites from each of the 3 localities are then averaged to produce a regional 'centroid'. Finally, the data from 2 sites from each of the 3 localities of each of the 3 regions were used to calculate an overall centroid. The advantage of this method over typical means of multi-scale comparison is that not every sample is used each time to calculate all possible inter-sample variability/dissimilarity values. Using this method, the data are independent for comparisons of scale. The different numbers of sample quadrats (sites) were used at each scale such that similar numbers (15) were used overall. Data from 5 of the 15 quadrats provide replicates to measure Bray-Curtis dissimilarity values from the locality centroid (between-site variability). Five different sets of site data can provide replicates to measure Bray-Curtis dissimilarity values from the region centroid (between site and locality variability), and the last 5 measure between site and between region dissimilarity based on comparison to the overall centroid. The method is displayed as a step process in Fig. 1.

As in Underwood \& Chapman (1998, see Table 3), it was not possible to standardise the overall centroid at $\mathrm{n}=15$ (overall centroid sample size was $\mathrm{n}=18$ ), because using 2 quadrats (sites) from each locality (the minimum to include replication) results in $2 \times 3$ (localities) $\times 3$ (regions) $=18$ samples. To standardise at $\mathrm{n}=15$ would involve only using data from 1 site at 3 of the 9 localities and these would therefore involve no replication. As 2 quadrats were used from each site, the overall centroid was, therefore, calculated on a higher sample size than any other centroid. The site numbers (15) were considered to be large enough for differences of $n=15$ compared to $\mathrm{n}=18$ to be trivial. For more details on centroid construction, see Underwood \& Chapman (1998).

Statistical treatment of data. Between site, between locality and between region analyses were performed on shell types at the (hermit crab) species level. The similarity values for locality, regional and overall centroids were used in ANOVA to test a null hypothesis of no difference at any spatial scale. The ANOVA thus comprises 1 factor (spatial scale) and 3 levels (between site, between locality and between region). 
Data on shell use of hermit crabs were compiled from the available literature (see Table 1). For global comparisons of similarity, data were transformed to family level for homology with the literature. Comparisons of variability were carried out using Levene's Homogeneity of variance test. No transformation of Bray-Curtis similarity, Shannon-Wiener index $H^{\prime}$ or Pielou's $J$ value was needed for ANOVA. Data were plotted as number of shell types used by hermit crabs with latitude. Each point represented the number of shell types used by 1 species, although only genera were indicated. Data were first categorised by genus and ocean (Atlantic vs Indo-Pacific), but then pooled. Although initially data from all genera were plotted, only those with clear patterns are illustrated. To correct for different numbers of species in different genera, $7 \pm 1$ species were used for each genus. Between genera and inter-oceanic comparisons were carried out using generalised linear model (GLM) ANOVA (see Goodnight 1976). Quadratic regressions (using ANOVA) were fitted to the resulting data to elucidate the degree of fit and relationship significance.
Niche space of hermit crabs (in terms of shell resource use) was examined using a standard ordination technique, correspondence analysis (see Preston 1962, Hill \& Gauch 1980). Typically the results of such techniques are presented as triplots or biplots depending on the cumulative variance explained by each axis. The technique arranges samples into multidimensional space. Points (i.e. hermit crab species samples) which are close together correspond to samples with similar shell-type use and points that are far apart correspond to samples that are dissimilar in shell-type use. The axes presented do not necessarily represent any particular factor, but various factors may be correlated with them. The advantage of such a process over traditional niche overlap indices is that all study species from all study countries can be simultaneously compared and overall niches of hermit crab species visualised. The average shell suites (proportional use of different shell types) of each hermit crab species from each region was subjected to ordination (untransformed) to examine trends across the Indian Ocean.

\section{$1.15 \times 4 \mathrm{~m}^{2}$ quadrats (= sites) taken at 3 localities at 3 regions to produce raw data \\ Region \\ Locality \\ Sites

\begin{tabular}{ccc}
\multicolumn{3}{c}{ N Mozambique } \\
1 & 2 & 3 \\
$1-15$ & $1-15$ & $1-15$
\end{tabular}

\begin{tabular}{ccc}
\multicolumn{3}{c}{ SW Madagascar } \\
1 & 2 & 3 \\
$1-15$ & $1-15$ & $1-15$
\end{tabular}

\begin{tabular}{ccc}
\multicolumn{3}{c}{ S Mozambique } \\
1 & 2 & 3 \\
$1-15$ & $1-15$ & $1-15$
\end{tabular}

2. Formation of centroids of average Bray-Curtis similarity

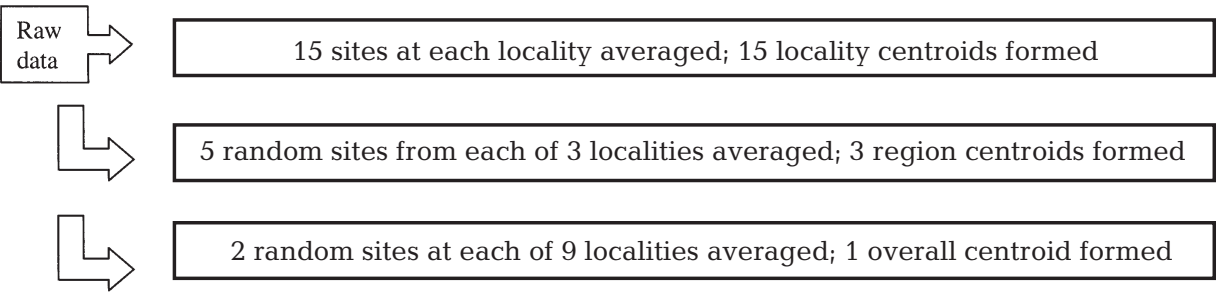

3. Analysis using Bray-Curtis to generate similarity values at each scale

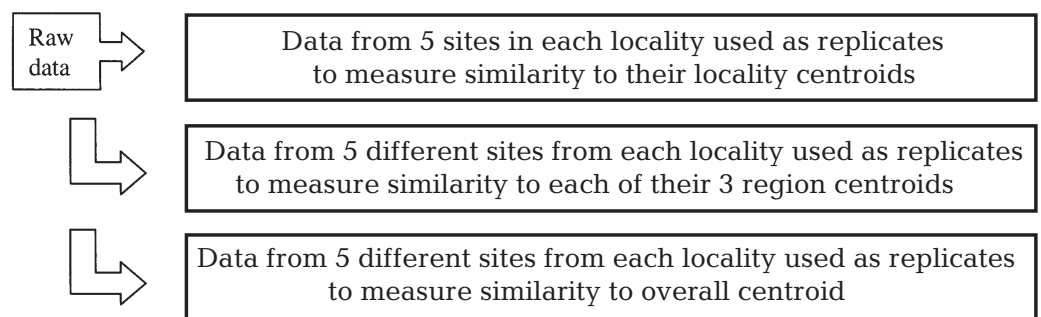

4. Statistical analysis of similarity values

ANOVA for each species-specific data (1 factor, 3 level)

Calculation of mean values for each scale and each region
Between site variability

Between site and locality variability

Between site and region variability 
Table 1. Localities and hermit crab species for which comparable shell-use data sets were available. Localities are ordered by latitude from most northerly (top) to most southerly (bottom)

\begin{tabular}{|c|c|c|}
\hline Region & Species & Source \\
\hline Norway & Pagurus cuanensis, P. prideauxi & Samuelsen (1970) \\
\hline Ireland & Pagurus bernhardus & Author's unpubl. data \\
\hline USA (Washington) & Pagurus granosimanus & Nyblade (1974) \\
\hline USA (Maine) & Pagurus acadianus & Grant (1963) \\
\hline Italy & Calcinus tubularis (= C. ornatus), Clibanarius erythropus & Gherardi (1990) \\
\hline USA (Rhode Island) & Pagurus longicarpus & Scully (1979) \\
\hline Japan & Clibanarius virescens, Pagurus geminus & Imazu \& Asakura (1994) \\
\hline Azores & Clibanarius erythropus & Botelho \& Costa (unpubl.) \\
\hline USA (North Carolina) & Pagurus longicarpus & Kellogg (1976) \\
\hline USA (South Carolina) & Pagurus longicarpus & Young (1979) \\
\hline USA (Florida) & Clibanarius antillensis, C. tricolor, Calcinus tibicen & Bach et al. (1976) \\
\hline Hong Kong & Clibanarius bimaculatus, Pagurus trigonocheirus & Siu \& Lee (1992) \\
\hline Red Sea & Coenobita scaevola & Niggerman (1968) \\
\hline Belize & Clibanarius tricolor, Calcinus tibicen & Fotheringham (1976) \\
\hline Cape Verde & Many species, 4 genera & Author's unpubl. data \\
\hline Enewetak (Micronesia) & Calcinus latens, Dardanus scutellatus, Diogenes gardineri & Orians \& King (1964) \\
\hline Costa Rica & Coenobita compressus & Kuris \& Brody (1976) \\
\hline Panama & Many species, 3 genera & Abrams 1978, Bertness (1982) \\
\hline Maldives & Calcinus laevimanus, C. latens, Clibanarius humilus & Gherardi \& Nardone (1997) \\
\hline \multirow[t]{2}{*}{ Kenya } & Many species, 4 genera & Author's unpubl. data \\
\hline & Clibanarius laevimanus & Gherardi \& Zatteri (1994) \\
\hline N Mozambique & Many species, 6 genera & This study \\
\hline S Brasil & Many species, 3 genera & Leite et al. (1998) \\
\hline SW Madagascar & Many species, 5 genera & This study \\
\hline S Mozambique & Many species, 3 genera & This study \\
\hline S Africa & Clibanarius virescens, Calcinus laevimanus & Reddy \& Biseswar (1993) \\
\hline
\end{tabular}

\section{RESULTS}

Comparative similarity of shell use with spatial scale ANOVA of Bray-Curtis similarity values showed significant differences amongst scales and between regions in the resource use of all 5 hermit crab species ( $\mathrm{S}$ in Table 2a-e). In all cases, mean Bray-Curtis similarity decreased with increasing scale, i.e. sites were most similar and regions were least similar. For the semi-terrestrial species Coenobita rugosus, there was $85 \%$ similarity between sites within each locality and about $74 \%$ similarity between localities within each region (Table 2a). Regions were more than $15 \%$ dissimilar than sites and nearly $7 \%$ more dissimilar than localities. Shell suite use of $C$. rugosus and all other study species except Calcinus laevimanus was quite variable but not significantly different at the scale of locality (1 km apart). Shell suites were most similar in sub-tropical southern Mozambique and least similar in tropical N Mozambique. Resource use similarity in SW Madagascar was only $3 \%$ more dissimilar than in $\mathrm{S}$ Mozambique. The analysis for shell use of Calcinus laevimanus showed many similar trends to that for $C$. rugosus (Table $2 \mathrm{~b}$ ). There was highly significant variability amongst scales and between regions. Sites (within localities) were most similar and regions were least similar. S Mozambique resource use had highest similarity and N Mozambique the lowest and Madagascar, again, between. The 2 essential differences between $C$. rugosus and $C$. laevimanus were that (1) there was significant difference between locality and between region variability, and (2) the similarity values at each scale were all lower in C. laevimanus. Shell suite use of the mainly subtidal species Calcinus latens was similar to the trends described for C. rugosus and C. laevimanus (Table 2c). The significance of (and proportion of variability explained by) betweenregion variability and, to a lesser extent, amongst-scale variability were lower. The level of similarity (between scales or regions) in C. latens resource use was also the lowest for any of the 5 species studied. Within locality site similarity was $\sim 60 \%$, while localities were slightly less similar and regions were least similar. The highest regional resource use similarity was S Mozambique, the middle of the 3 regions was SW Madagascar and N Mozambique was the lowest.

Although there was also highly significant variability amongst scales and between regions in Clibanarius longitarsus in mangrove swamps, there was also significant interaction between spatial scales and region (Table 2d). This indicates that differences between scales varied with region and thus, are difficult to 
Table 2. ANOVA of Bray-Curtis dissimilarities of resource use between randomly selected sites, localities and regions. No. of sites (sample unit) for calculating similarities for each scale in each locality: 5 in a-c; 3 in d,e. No. of sites used for estimation of centroids in each locality, region, and overall: 15, 15, 18 in a-c; 12, 12, 18 in d,e

\begin{tabular}{|c|c|c|c|c|}
\hline \multicolumn{5}{|l|}{ (a) Coenobita rugosus } \\
\hline Source of variation & df & MS & $F$-ratio & $\mathrm{p}$ \\
\hline Amongst scales (S) & 2 & 9650.9 & 686.0 & $<0.001$ \\
\hline Between regions (R) & 2 & 72.8 & 4.3 & $<0.003$ \\
\hline Between Localities (regions) L(r) & 6 & 18.0 & 1.1 & 0.39 \\
\hline $\mathrm{S} \times \mathrm{R}$ & 4 & 10.9 & 0.6 & 0.53 \\
\hline $\mathrm{S} \times \mathrm{L}(\mathrm{r})$ & 12 & 5.5 & 0.3 & 0.9 \\
\hline Residual & 108 & 17.1 & - & \\
\hline Total & 134 & - & & \\
\hline Mean (SE); $\mathrm{n}=45$ & $\begin{array}{c}\text { Site } \\
85.0(0.8)\end{array}$ & $\begin{array}{l}\text { Locality + Site } \\
\quad 74.2(0.8)\end{array}$ & $\begin{array}{c}\text { Region + Locality + Site } \\
56.9(0.6)\end{array}$ & \\
\hline Mean (SE); $\mathrm{n}=45$ & $\begin{array}{c}\text { N Mozambique } \\
68.0(2.6)\end{array}$ & $\begin{array}{c}\text { SW Madagascar } \\
73.2(2.3)\end{array}$ & $\begin{array}{c}\text { S Mozambique } \\
75.8(2.8)\end{array}$ & \\
\hline \multicolumn{5}{|l|}{ (b) Calcinus laevimanus } \\
\hline Source of variation & df & MS & F-ratio & $\mathrm{p}$ \\
\hline Amongst scales (S) & 2 & 1243.1 & 15.2 & $<0.001$ \\
\hline Between regions $(\mathrm{R})$ & 2 & 657.2 & 8.0 & $<0.001$ \\
\hline Between Localities (regions) L(r) & 6 & 180.2 & 2.2 & $<0.05$ \\
\hline $\mathrm{S} \times \mathrm{R}$ & 4 & 42.5 & 0.5 & 0.72 \\
\hline $\mathrm{S} \times \mathrm{L}(\mathrm{r})$ & 12 & 48.2 & 0.6 & 0.85 \\
\hline Residual & 108 & 81.9 & - & \\
\hline Total & 134 & - & & \\
\hline Mean $(\mathrm{SE}) ; \mathrm{n}=45$ & $\begin{array}{c}\text { Site } \\
75.8(1.6)\end{array}$ & $\begin{array}{l}\text { Locality + Site } \\
\quad 70.0(1.4)\end{array}$ & $\begin{array}{c}\text { Region + Locality + Site } \\
65.5(1.6)\end{array}$ & \\
\hline Mean $(\mathrm{SE}) ; \mathrm{n}=45$ & $\begin{array}{c}\text { N Mozambique } \\
67.3(2.2)\end{array}$ & $\begin{array}{c}\text { SW Madagascar } \\
68.8(2.2)\end{array}$ & $\begin{array}{c}\text { S Mozambique } \\
75.6(2.4)\end{array}$ & \\
\hline \multicolumn{5}{|l|}{ (c) Calcinus latens } \\
\hline Source of variation & df & MS & F-ratio & $\mathrm{p}$ \\
\hline Amongst scales (S) & 2 & 276.4 & 5.8 & 0.008 \\
\hline Between regions $(\mathrm{R})$ & 2 & 216.2 & 3.9 & 0.023 \\
\hline Between Localities (regions) L(r) & 6 & 33.5 & 0.6 & 0.727 \\
\hline $\mathrm{S} \times \mathrm{R}$ & 4 & 23.2 & 0.4 & 0.796 \\
\hline $\mathrm{S} \times \mathrm{L}(\mathrm{r})$ & 12 & 15.9 & 0.3 & 0.990 \\
\hline Residual & 108 & 55.5 & - & \\
\hline Total & 134 & - & & \\
\hline Mean $(\mathrm{SE}) ; \mathrm{n}=45$ & $\begin{array}{c}\text { Site } \\
59.9(1.4)\end{array}$ & $\begin{array}{l}\text { Locality + Site } \\
\quad 57.1(0.9)\end{array}$ & $\begin{array}{c}\text { Region + Locality + Site } \\
54.1(0.9)\end{array}$ & \\
\hline Mean (SE); $\mathrm{n}=45$ & $\begin{array}{c}\text { N Mozambique } \\
54.9(1.5)\end{array}$ & $\begin{array}{c}\text { SW Madagascar } \\
56.2(1.4)\end{array}$ & $\begin{array}{c}\text { S Mozambique } \\
60.2(1.7)\end{array}$ & \\
\hline \multicolumn{5}{|l|}{ (d) Clibanarius longitarsus } \\
\hline Source of variation & df & MS & $F$-ratio & $\mathrm{p}$ \\
\hline Amongst scales (S) & 2 & 2861.4 & 236.1 & $<0.001$ \\
\hline Between regions $(\mathrm{R})$ & 2 & 3507.0 & 289.4 & $<0.001$ \\
\hline Between Localities (regions) L(r) & 6 & 21.1 & 1.7 & 0.118 \\
\hline $\mathrm{S} \times \mathrm{R}$ & 4 & 68.1 & 5.62 & $<0.001$ \\
\hline $\mathrm{S} \times \mathrm{L}(\mathrm{r})$ & 12 & 15.4 & 1.3 & 0.248 \\
\hline Residual & 108 & 12.1 & - & \\
\hline Total & 134 & - & & \\
\hline Mean (SE); $\mathrm{n}=45$ & $\begin{array}{c}\text { Site } \\
85(1.3)\end{array}$ & $\begin{array}{c}\text { Locality + Site } \\
76.6(1.5)\end{array}$ & $\begin{array}{c}\text { Region + Locality + Site } \\
69.9(1.1)\end{array}$ & \\
\hline
\end{tabular}


Table 2 (continued)

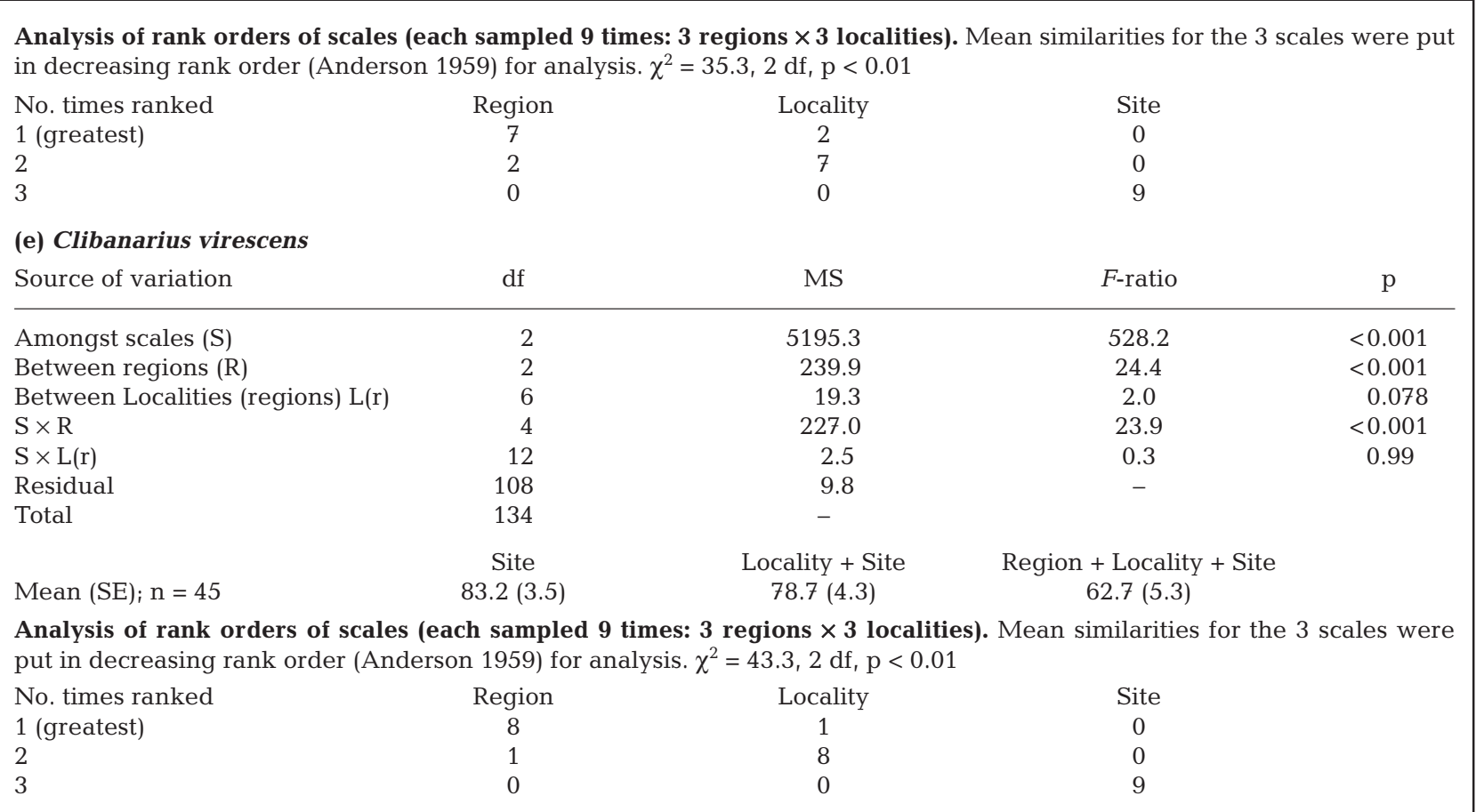

interpret except within each study region. Analysis of rank orders of scales showed, however, that similarity was higher between sites than between localities than between regions (Anderson [1959] test, $\chi^{2}=35.3,2 \mathrm{df}$, $\mathrm{p}<0.01$ ). Shell use in the third eulittoral species Clibanarius virescens was very similar to that of congeneric C. longitarsus. ANOVA of C. virescens Bray-Curtis similarity scores showed highly significant variability amongst scales, between regions and in the interaction between scale and region (Table 2e). The significance of such an interaction term negates more analysis other than similarity was demonstrably higher between sites than between localities than between regions (Anderson [1959] test, $\chi^{2}=43.3,2 \mathrm{df}, \mathrm{p}<0.01$ ).

The similarity of ANOVA results of Bray-Curtis values for each of the 5 species, despite taxanomic and habitat differences, suggests that the overall trends in resource use similarity are real. All the ANOVAs concerning variability of shell use similarity were intraspecific, but types of shell used differ with overlap interspecifically. Inclusion of species into a 2-factor, 3-level ANOVA showed hermit crab shell suites were less similar to each other between regions than between species $(F$-ratio $=5.1, \mathrm{p}=0.038)$. Correspondence analysis of the SW Madagascar and N Mozambique shell suite data (for each study species, for each study region) supported the findings of ANOVA on Bray-Curtis values. Only the first 3 axes of the analyses were used for interpretation (Fig. 1) with eigenvalues of $0.35,0.22$ and 0.17 , respectively (explaining $77 \%$ of cumulative variance). The results showed localities to mostly group within distinct regional and species clusters (Fig. 2). The shell suite used by each species of hermit crab formed 2 regional clusters, but the similarity of these 2 clusters (shown as proximity in Fig. 2) varied with species identity. The 2 regional clusters were most similar in Coenobita rugosus and Clibanarius virescens and least similar in Clibanarius longitarsus. Only 1 cluster was composed of 2 species; C. virescens and Calcinus latens in Madagascar. While all other species at all regions showed evidence of discrete resource (shell) partitioning $C$. virescens and C. latens clearly have substantial overlap in Madagascar. The overlap of the 2 Calcinus laevimanus clusters (dark grey triangles and circles in Fig. 2) have no impact on resource partitioning as the 2 populations were separated in space.

\section{Region, locality and site variability in shell use}

Shell diversity (Shannon-Wiener index, $H^{\prime}$ ) used by the 5 study species of hermit crab varied between 2.54 and 0.94 in N Mozambique, 2.4 and 0.1 in SW Madagascar, and 2.1 and 0.11 in S Mozambique. GLM indicated no significant differences at site level in any species in diversity of resource use. In addition, no significant differences were shown at regional or 


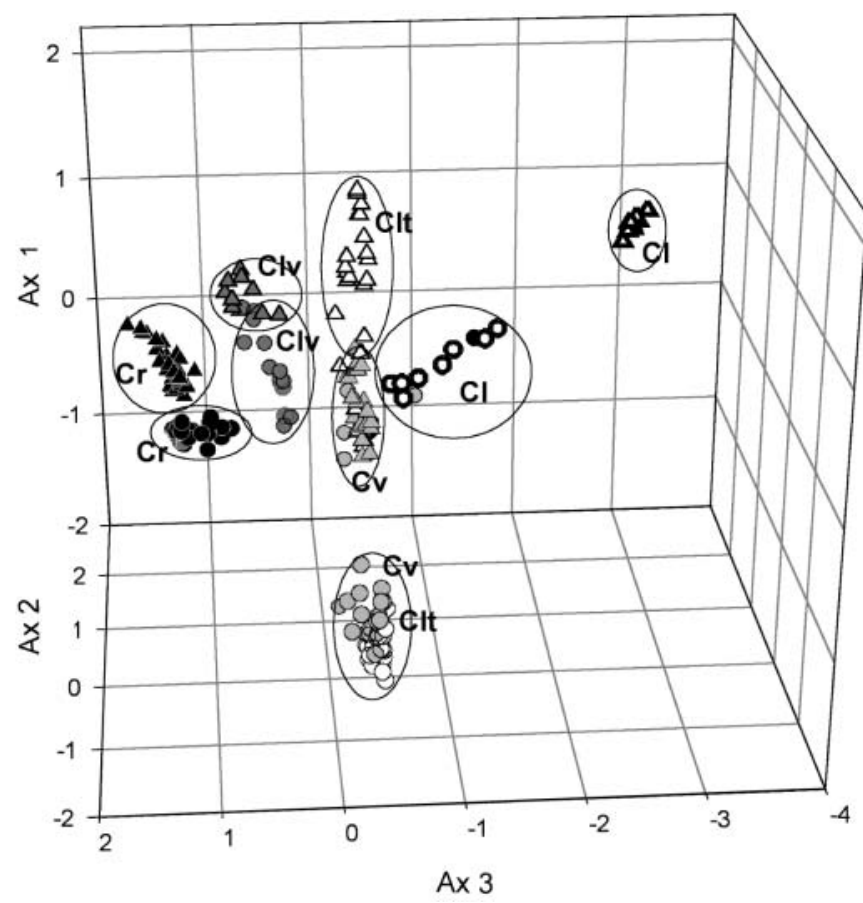

Fig. 2. Correspondence analysis of Mozambique and Madagascar hermit crab resource use. Positions of samples are indicated and coded according to region (triangles = Mozambique, circles = Madagascar) and species (black: Coenobita rugosus $[\mathrm{Cr}]$; dark grey, Calcinus laevimanus $[\mathrm{Clv}]$; white, Calcinus latens [Clt]; white with thick black surround, Clibanarius longitarsus $[\mathrm{Cl}]$; light grey, Clibanarius virescens $[\mathrm{Cv}]$. Encircled clusters are based on visual proximity of points and represent the 'central cluster' for each particular species (some outlying points may, therefore, not be encircled)

locality level in the semi-terrestrial species (Coenobita rugosus) and the lower-shore species (Calcinus latens). There were, however, significant differences (in diversity and evenness of resource use) at both regional and locality level in the 2 eulittoral Clibanarius species (Table 3a). In each case, the regional level difference was more explanatory of data variability (regional GLM $F$-ratio $\gg$ locality GLM $F$-value). In the other eulittoral species, Calcinus laevimanus, significance was only found at regional level (Table 3a). Evenness of shell use (Pielou's $J$ value) varied similarly with values between 0.99 and 0.53 in N Mozambique, 0.88 and 0.1 in SW Madagascar and 0.82 and 0.1 in S Mozambique. GLM ANOVA values showed that, in contrast to $H^{\prime}$ diversity values, regional evenness was significantly different in all study species. The same was also true of locality evenness, although (with 1 exception) the $F$ ratios and p-values were all lower than regional level differences (Table 3a). Evenness was the only variable measured which showed regional and locality level differences in all the study species.
The region with most (but not significantly so) shell types used, and with the highest diversity and evenness values, was N Mozambique (18 to 5 range). The lowest shell types usage, diversity and evenness values were in S Mozambique (13 to 3 range) and the equivalent values from SW Madagascar (17 to 3) were in between. The numbers of living molluscs found in the sample sites showed a similar regional pattern; 41 in N Mozambique, 37 in SW Madagascar and 31 in $\mathrm{S}$ Mozambique. The number of empty mollusc shells was more similar between regions: 32, 26 and 25. The maximum proportion of empty shell types available used by any hermit crab species in any region was $<66 \%$ (56 to 16,65 to 11.5 and 52 to $12 \%$ for N Mozambique, SW Madagascar and S Mozambique, respectively). While GLM ANOVA tests on shell-use data showed the 3 eulittoral species to exhibit the most significant differences in $H^{\prime}$ and $J$ values at regional and local levels, this was not true for number of shells used. The most significant differences were found in the species Clibanarius longitarsus for all variables measured. Coenobita rugosus, the semiterrestrial species, which used the most shell types, showed the most significant regional and the only locality variability.

Clibanarius longitarsus had the highest proportional $(98 \%)$ use of a single shell type and as a result of the magnitude of this value also had the highest proportional use of the top 2 shell types (99\%). The other Clibanarius species, $C$. virescens had the lowest equivalent values with a maximum of 19 and $30 \%$ for its single and 2 most used shell types, respectively. Again, the 3 eulittoral species showed the greatest and most significant differences between areas in terms of the dominance of the most used shell types (Table 3b). For the 2 hermit crab species in which locality differences were also found, they were always of lower $F$ - and $\mathrm{p}$-values than the equivalent values for region.

Clibanarius longitarsus used the highest proportion (39\%) of damaged shells and Coenobita rugosus the least $(3 \%)$, but there were no significant differences at regional, locality or site level in their usage; hence, no $F$-values are shown in this section of Table $3 b$.

\section{Global (inter-oceanic and latitudinal) trends}

The numbers of shell types used by hermit crabs had a strongly taxon-specific component; Dardanus, Diogenes and Pagurus species used fewer shell types than Coenobita, Clibanarius and Calcinus species $($ GLM ANOVA, F-ratio $=108, \mathrm{p}<0.001)$. No interoceanic trends were apparent, but this may have resulted from the confounding influence of differential sampling localities in the Atlantic and Indo-Pacific 
Table 3. Various hermit crab species. Table of significant ANOVA F-values for between region (R), between locality (L) and between site (S) comparisons of (a) resource use and (b) shell dominance. The significances associated with $F$-values are ${ }^{*} \mathrm{p}<0.05,{ }^{* *} \mathrm{p}<0.01$ and ${ }^{* * *} \mathrm{p}<0.001$

\begin{tabular}{|c|c|c|c|c|c|c|c|c|c|}
\hline \multirow[t]{2}{*}{ (a) Resource use } & \multicolumn{3}{|c|}{ Diversity $\left(H^{\prime}\right)$} & \multicolumn{3}{|c|}{ Evenness $(J)$} & \multicolumn{3}{|c|}{ No. shell types } \\
\hline & $\mathrm{R}$ & $\mathrm{L}$ & $\mathrm{S}$ & $\mathrm{R}$ & $\mathrm{L}$ & $\mathrm{S}$ & $\mathrm{R}$ & $\mathrm{L}$ & $\mathrm{S}$ \\
\hline Coenobita rugosus & & & & $3.8^{*}$ & $11.8^{* *}$ & & $14.3^{* *}$ & $4.5^{*}$ & \\
\hline Clibanarius longitarsus & $493^{* * *}$ & $20.2^{*}$ & & $191^{* * *}$ & $17.2^{* *}$ & & $99^{* * *}$ & & \\
\hline Clibanarius virescens & $16.1^{* *}$ & $7.4^{*}$ & & $37^{* * *}$ & $34^{* * *}$ & & $10.4^{* *}$ & & \\
\hline Calcinus laevimanus & $24^{* * *}$ & & & $34^{* * *}$ & $4.7^{*}$ & & & & \\
\hline Calcinus latens & & & & $7.0^{* *}$ & $4.8^{*}$ & & & & \\
\hline \multirow[t]{2}{*}{ (b) Shell dominance ${ }^{a}$} & \multicolumn{3}{|c|}{ Most used shell } & \multicolumn{3}{|c|}{ Top 2 shells } & & & \\
\hline & $\mathrm{R}$ & $\mathrm{L}$ & $\mathrm{S}$ & $\mathrm{R}$ & $\mathrm{L}$ & $\mathrm{S}$ & & & \\
\hline C. longitarsus & $257^{* * *}$ & $11.6^{* *}$ & & $368^{* * *}$ & $12.7^{* *}$ & & & & \\
\hline C. virescens & $5.9^{* *}$ & & & $7.2^{*}$ & & & & & \\
\hline C. laevimanus & $20.5^{* * *}$ & $13^{* *}$ & & $34.5^{*}$ & & & & & \\
\hline C. latens & $4.2^{*}$ & & & & & & & & \\
\hline
\end{tabular}

for the genera Coenobita, Clibanarius and Calcinus. Equally the paucity of data on Dardanus, Diogenes and Pagurus makes inter-ocean comparisons difficult, but in none of them is there any suggestion of larger shell numbers being used in either ocean realm. There was, however, a suggestion of differential numbers of shells in the suites used with latitude. The data were pooled across oceans due to the lack of significant difference between Atlantic and Indo-Pacific samples (GLM ANOVA, F-ratio $=0.6, p>0.05$ ). The tropical/subtropical genus Coenobita did not show any latitudinal trend, but the more widespread species did show significant trends. Both Clibanarius spp. and Calcinus spp. used significantly more shell types at tropical low latitudes than temperate high latitudes (quadratic regressions both $\mathrm{p}<0.028$; Fig. 3 ). Despite the significance of the latitudinal trend in shell use in these 2 species, the $\mathrm{r}^{2}$ values $(0.29$ and 0.24 , respectively) associated with the regressions show this relationship to explain only a small proportion of the data variance.

Few data are available from the literature which describe shell suites of the same hermit crab species (rather than genus) from different regions. Including the data from the present study, only 6 hermit crab species (all Indo-Pacific) known to the author have shell suites recorded from at least 5 different regions. These species, Coenobita rugosus, Calcinus laevimanus, Calcinus latens, Clibanarius virescens, Dardanus megistos and Diogenes gardinieri, all use significantly different numbers of shell types across these regions (ANOVAs all $p<0.05$ ). Only the first 2 axes were extracted from correspondence analysis with eigenvalues of 0.36 and 0.14 (which together explained $68 \%$ of cumulative variance). The most striking pattern to emerge from correspondence analysis of shell suites was that hermit crab species identity was most important in the subtidal species (Dardanus megistos and Diogenes gardinieri), whereas intertidal species clustered by region (Fig. 4). Notably, the regions typically split into the islands (Mascarenes) versus the African mainland. The 2 data points for South Africa, despite being for

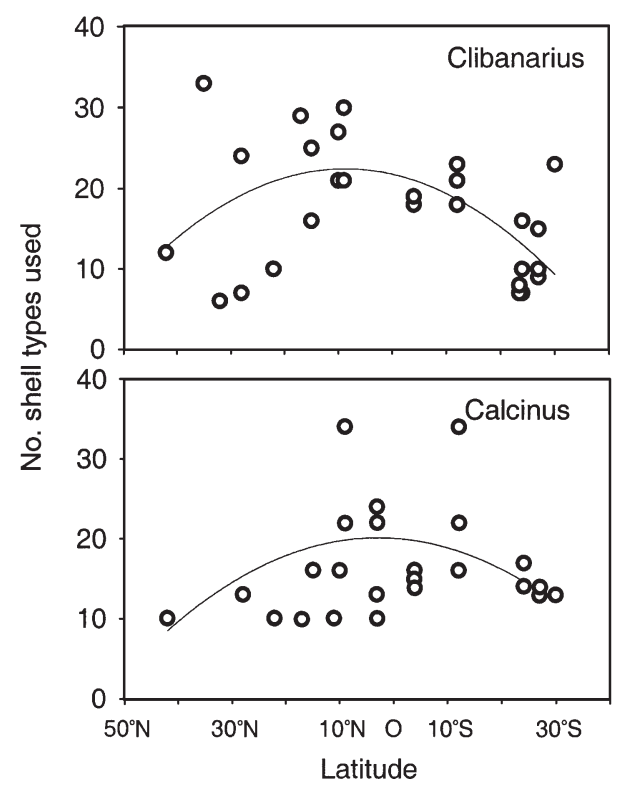

Fig. 3. Clibanarius spp. and Calcinus spp. Parabolic relationship between variability of resource use and latitude. Data are pooled across oceans (see Fig. 2 and accompanying text) and are taken from present study and literature (see Table 1). Both regression lines are significant at $p<0.05$ level and $r^{2}$ values are 0.3 (top) and 0.25 (bottom) 


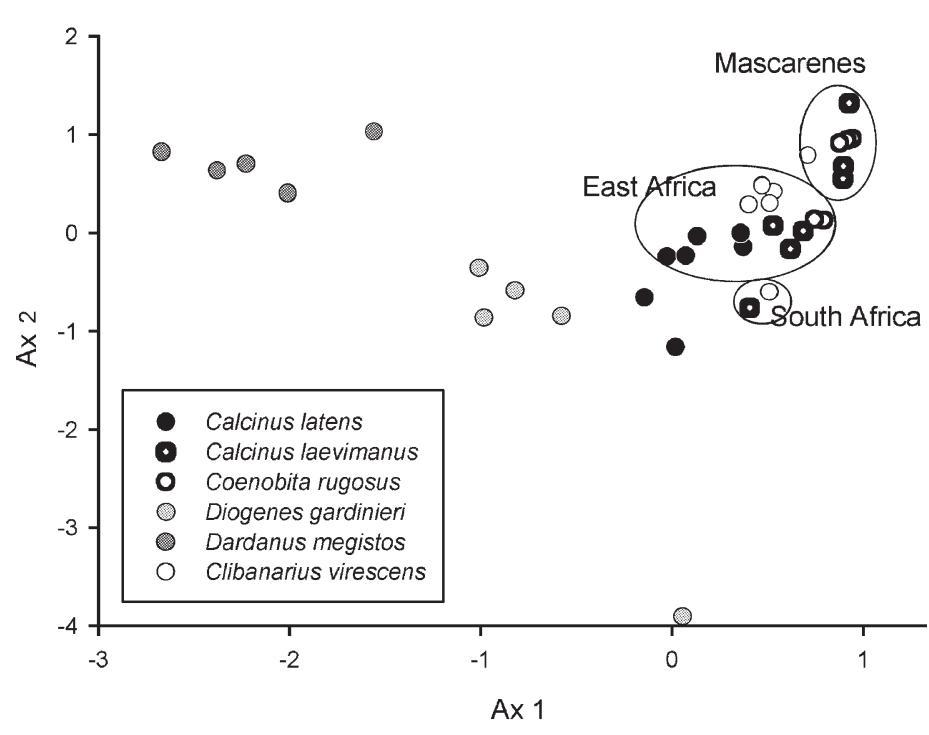

Fig. 4. Correspondence analysis of Indian Ocean hermit crab resource use; data from present study and the literature (see Table 1). For details of eigenvalues and cumulative variance explained by axes see 'Results'. Encircled clusters demonstrate regional convergence in shell-resource use by some hermit crab species. The circles are based on visual proximity of points for the Calcinus, Clibanarius and Coenobita species. The Dardanus and Diogenes species did not cluster by region and were therefore not encircled

different species, were closer than to other African mainland points. The greatest outlying single point was Diogenes gardinieri in the Maldives.

\section{DISCUSSION}

\section{Variability of resource use with species' biology}

Typically, organism resource requirements are considered to differ interspecifically, although a degree of overlap may exist between species with similar ecology or phylogeny. Overall niche separation or distinctness for each species depends on the degree of overlap across all resources utilised by each species. Certain animals, such as hermit crabs, are quite generalist and opportunist with respect to many resources, but quite specific to one (food and gastropod shells, respectively). Hermit crabs, which require a sequential series of gastropod shells of increasing size for their own growth, generally have species-specific preference for shell attributes (Reese 1962). The shell types used by specific hermit crab species may be a result of the biology of: (1) local gastropod species, (2) their predators or (3) the hermit crabs themselves. The present study demonstrates variability in hermit crab resource use changes with spatial scale considered. This finding is likely to be robust as was true in species from different genera (and families), habitats and lifestyle (semi-terrestrial to subtidal).

So does observed variability in hermit crab resource use link strongly to the biology of the particular study species? Opportunities and creating opportunities for resource acquisition are likely to be fundamental, especially as most populations are shell restricted (Kellogg 1976). A few hermit crab species can procure shells from living gastropods (Rutherford 1977); none, however, was observed to in the current study. Similarly, only a few use fossil shells (Barnes 2001), but this explains less than $1 \%$ of shell use by just 2 of the study species; therefore, it is unlikely to be a major factor. Busato et al. (1998) showed how more mobile species increased variability in chance (and quality) of local resource acquisition. The mobility of the study species was certainly very different, but the most mobile were Coenobita rugosus and Calcinus longitarsus, which used the most and fewest shell types, respectively. Across the literature, however, species of Coenobita, Clibanarius and Calcinus (which are all fairly mobile) generally used more types of shell than others, such as species of Dardanus, Diogenes and Pagurus (which are less so). Other processes less stochastic in nature than opportunity may also be important at multiple spatial scales for variability in resource use. Previously described species differences in specific hermit crab biology, which may also be relevant to the species in the current study, include resistance to predation (Bertness 1982) or environmental extremes (Gherardi 1990) and shore level inhabited (Reddy \& Bisewar 1993). In addition, hermit crabs species have different preferences for shell geometry, volume, aperture width, strength, mass, condition or other features of particular shells (Reese 1962, 1969, Conover 1978, Borjesson \& Szelistowski 1989, Pechenik \& Lewis 2000). Species-specific patterns of resource use did emerge as a strong explanatory variable behind the data of the present study. One of the major problems for interpreting which aspects of environment or species biology are most important in explaining observed patterns is the extent to which factors are confounding. Users of many shell types such as Coenobita, Clibanarius and Calcinus occur at higher shore levels, are more mobile, experience different predators and resources than species of the subtidal genera Dardanus, Diogenes and Pagurus. Speciesspecific components of shell use were more significant and explanatory of data in the present study than smaller scale spatial parameters. Nevertheless, the null hypothesis that species-specific patterns would be more important than any of spatial nature can be rejected. The underlying importance of geographic elements to resource allocation and utilisation was underlined by the emergence of region as the most significant overall influence on hermit crab resource use variability. 


\section{Variability of resource use with geography}

For the resource attributes focussed on in this study, variability was most apparent at regional and global levels. The null hypothesis was accepted that variability at regional > locality $>$ site level. The significance of differences in shell suites at locality level, in addition to region, could confound potential conclusions. However, variance explained at regional level $\gg$ locality level and the former was significant in 18 comparisons compared with 11 of the latter (Table 3).

At large scale, latitudinal but not longitudinal (inter-oceanic) patterns in resource use were demonstrated here. Interpretation of this pattern is not, however, simple. Are the trends with latitude simply reflective of a gradient in gastropod diversity (Stehli et al. 1967, Roy et al. 1998, Crame 2000), availability, longevity or even preferences by hermit crabs? Unfortunately, with the exception of the former, few of these have been established for many localitiesexcept that hermit crabs are typically shell restricted. The only strong latitudinal cline shown in gastropods to date (Roy et al. 1998) concentrated on a different continent (North America) and hemisphere (northern) to that of the present study. To the author's knowledge, no comprehensive diversity data have been shown for any marine taxon on either East or West coasts of Africa. At a global level, the current data can only be compared with trends in deepwater macrofauna (Rex et al. 1993) or bivalves (Crame 2000), both of which demonstrate a clear latitudinal cline, but again only in the northern hemisphere. Therefore, in terms of latitude, there is just not enough comprehensive data in the literature to generate an expected trend in the southern hemisphere (Gray 2001), especially on African coasts.

Roy et al. (1998) found some variability in gastropod species richness between American coasts and Bertness (1982) found between-ocean differences in hermit crab shell use each side of the Panama Isthmus. The present study, in contrast to those, found no suggestion of an inter-oceanic effect. This should not be surprising, however, for a number of reasons. First, the number of shell types used by most hermit crabs is small (usually $<30$ per species) in comparison with the number of gastropod species inhabiting most coastal regions (only a maximum of $46 \%$ of living and $65 \%$ of available empty gastropod species in this study). Second, even when shell restricted, they may use as many shell types as when virtually unrestricted (Bertness 1982, cf. Barnes 1999). Third, that no significant inter-oceanic effects emerged may simply reflect the parameters compared in this study.

\section{Causation of differential shell use patterns}

In the present study, more shell types were used either at lower latitudes or by species belonging to certain genera. There is a bewildering array of resource, resource-user and environmental factors, particularly in the case of the hermit-crab shell dyade, which can confound any simple explanation. Some problems, such as some genera being more speciose or easier to study than others, can be corrected for, to some extent, by selective use of the literature to standardise sample size. Other problems, which underlie explanation of the latitudinal cline (and other global trends), such as unknown variability in classification accuracy (between different studies) and enforced use of genus level resolution (rather than species) cannot be allowed for. Most explanations for hermit crab shell use or choice have centred on the nature of shells chosen rather than variety. Predation remains one of the dominant biological factors explaining shell use in studies thus far (Reese 1969, Vance 1972, Borjesson \& Szelistowski 1989), despite a virtual absence of direct evidence. Global trends in predation have been considered to be causal of differential shell morphology (Vermeij 1976) and type of shell use by hermit crabs (Bertness 1982). In some cases, predation may be the 'driving' factor effecting variation in resource selection, but this cause can be masked by variability in another (unrelated) factor. Two sympatric hermit crab species, studied by Busato et al. (1998), preferred the (same) most effective antipredator shells, but occupied different shells due to variation in hermit crab mobility. Even if predation or environmental pressure is greater in the tropics (which is doubted by many, e.g. McGuiness 1990) and thus, by inference, more influential on hermit crab shell choice at low latitude (Bertness 1981, Bojesson \& Szelistowski 1989), why should tropical crabs use more types of shells? Possibly, it is no more complex than they have access to more shell types there. Latitudinal variation of living gastropod species richness seems the most likely explanation for tropical peaks in hermit crab use (Fig. 3). While a latitudinal cline in resource use is demonstrated, its cause has not, although effects, at least, of high tropical use, are of great importance to niche space and species co-existence.

\section{Implications for niche overlap and co-existence}

Abrams' (1980) suggested that individualised (species) and important resource use differences probably had a major role in niche segregation. Field studies, like that reported here (Fig. 2), by Leite et al. (1998) and Barnes \& De Grave (2000) have provided some support for this idea. The many species of littoral gas- 
tropods (in the Indo-west-Pacific study region) could reduce potential competition between hermit crabs occurring in the same area. If this was the case, the wide choice of resources could also explain why so many hermit crabs species can exist in such large numbers in such areas (Gherardi \& Nardone 1997, Leite et al. 1998). Whether shell diversity does reduce competition is debatable (Grant \& Ulmer 1975, Hazlett 1981) as shell supply is typically exceeded by demand (Kellogg 1976, Bertness 1981); therefore, optimal choices are not always achieved. Barnes \& De Grave (2000) showed little overall overlap in resource use by 7 species coincident in occurrence (in Mozambique), although the hermit crab shell-use patterns formed a tight niche-mosaic.

Other studies have focussed on species co-existence mediated by spatial separation (Gherardi \& Nardone 1997, De Grave \& Barnes 2001). Current data suggest that resource-use variability along multi-scale spatial gradients are, however, at least as important as taxonomic identity. Spatial parameters may be important in different ways as they are least significant at the local level. Sometimes animals of similar size, trophic status and closely related taxonomy may overlap in space and time, apparently fulfilling very similar ecological roles. How such species co-exist and what critical differences separate apparently similar species are fundamental questions for ecologists. On many subtropical and tropical shores, hermit crabs may dominate numbers of individuals and macro-benthic species, despite utilising similar resources (gastropod shells, food and habitat). Subtle differences in (shell) resource utilisation in combination with habitat use may be vital in resource partitioning at local scale (see e.g. Vance 1972, Abrams 1987, Gherardi \& Nardone 1997, Barnes \& De Grave 2000, De Grave \& Barnes 2001), and possible niche definition and long-term species survival at higher spatial scales.

The present study concludes that East African hermit crabs show coherent variability amongst scales and between regions, which is robust across species and environments. Certain patterns (number of shell-types used) may reflect major trends in ecology (diversity clines with latitude and/or predation intensity). The problem is that this example of resource user and resource has too many complexities for simple explanations. New or new adaptations of statistical techniques (as here, but see also Underwood \& Chapman 1998, Barnes \& De Grave 2000) are greatly increasing the power, meaningfulness and resolution of studies as well as provoking critical discussion on experimental rationale. This study shows strong species-specific and spatial components influence patterns of resource use from local to regional scale (and possibly global); however, how much of the variability do these factors explain? To better understand overall importance of taxa, resource use and space effects, a third factor influencing variability must be considered, namely, time. The method of the present study could be adapted to do this.

Acknowledgements. The author wishes to thank all the scientific staff, logistic staff and volunteer research assistants of the Frontier Mozambique and Frontier Madagascar Marine Research Programmes, Rod and Helen Arnold, and Jo and Finn Barnes. Frontier Madagascar is a collaborative venture between the Society for Environmental Exploration (SEE) in the UK and the Institut Halieutique et des Sciences Marines (Universite de Toliara). I also wish to thank Damon StanwellSmith for making both visits possible.

\section{LITERATURE CITED}

Abrams P (1978) Shell selection and utilisation in a terrestrial hermit crab, Coenobita compressus (M. Milne Edwards). Oecologia 34:239-253

Abrams P (1980) Resource partitioning and interspecific competition in a tropical hermit crab community. Oecologia 46:365-379

Abrams P (1987) Resource partitioning and competition for shells between intertidal hermit crabs on the outer coast of Washington State. Oecologia 72:248-258

Anderson RL (1959) Use of contingency tables in the analysis of consumer preference studies. Biometrics 15:582-590

Bach C, Hazlett B, Rittscoff D (1976) Effects of interspecific competition on the fitness of the hermit crab Clibanarius tricolor. Ecology 57:579-586

Barnes DKA (1999) The ecology of tropical hermit crabs at Quirimba Island, Mozambique: shell characteristics and utilisation. Mar Ecol Prog Ser 183:241-251

Barnes DKA (2001) Ancient homes for hard-up hermit crabs. Nature 412:785-786

Barnes DKA, De Grave S (2000) Ecology of tropical hermit crabs at Quirimba Island, Mozambique: niche width and resource allocation. Mar Ecol Prog Ser 206:171-179

Barnes DKA, Corrie A, Whittington M, Carvelho MA, Gell F (1998) Coastal shellfish resource use in the Quirimba Archipelago, Mozambique. J Shellfish Res 17:51-58

Bertness MD (1981) Predation, physical stress, and the organisation of a tropical hermit crab community. Ecology 62: 411-425

Bertness MD (1982) Shell utilization, predation pressure, and thermal stress in Panamanian hermit crabs: an interoceanic comparison. J Exp Mar Biol Ecol 64:159-187

Borjesson DL, Szelistowski WA (1989) Shell selection, utilization and predation in the hermit crab Clibanarius panamensis Stimpson in a tropical mangrove estuary. J Exp Mar Biol Ecol 133:213-228

Briggs JC (1987) Marine zoogeography. McGraw-Hill, New York, p 475

Busato P, Benvenuto C, Gherardi F (1998) Competitive dynamics of a Mediterranean hermit crab assemblage: the role of interference and exploitative competition for shells. J Nat Hist 32:1447-1451

Conover M (1978) The importance of various shell characteristics to the shell selection behaviour of hermit crabs. J Exp Mar Biol Ecol 32:131-142

Crame JA (2000) Evolution of taxonomic diversity gradients in the marine realm: evidence from the composition of recent bivalve faunas. Paleobiology 26:188-214 
De Grave S, Barnes DKA (2001) The ecology of tropical hermit crabs at Quirimba Island, Mozambique: a multivariate perspective. Trop Zool 14:197-209

Fotheringham N (1976) Population consequences of shell limitation by hermit crabs. Ecology 57:570-578

Gherardi F (1990) Competition and coexistence in two Mediterranean hermit crabs, Calcinus ornatus (Roux) and Clibanarius erythropus (Latreille) (Decapoda, Anomura). J Exp Mar Biol Ecol 143:221-238

Gherardi F, McLaughlin PA (1994) Shellow water hermit crabs (Crustacea: Decapoda: Anomura: Paguridea) from Mauritius and Rodrigues Island, with description of a new species of Calcinus. Raffles Bull Zool 42:613-656

Gherardi F, Nardone F (1997) The question of coexistence in hermit crab population ecology of a tropical intertidal assemblage. Crustaceana 70:608-629

Gherardi F, Zatteri M (1994) Hermit crabs in a mangrove swamp: the structure of Clibanarius laevimanus clusters. Mar Biol 121:41-52

Goodnight JH (1976) The new general linear models procedure. Proc 1st Int SAS Users' Conf. SAS Institute, Cary, NC

Grant WC (1963) Notes on the ecology and behavior of the hermit crab Pagurus acadianus. Ecology 44:767-771

Grant WC, Ulmer KM (1975) Shell selection and aggressive behaviour in two sympatric species of hermit crabs. Biol Bull 146:32-43

Gray JS (2001) Marine diversity: the paradigms in patterns of species richness examined. Sci Mar 65:41-56

Hazlett BA (1981) The behavioural ecology of hermit crabs. Annu Rev Ecol Syst 12:1-22

Hilgendorf F (1878) Die von Hrn. W. Peters in Moçambique gesammelten Crustaceen. Monatsber Dtsch Akad Wiss Berl 25:782-850

Hill MO, Gauch HG (1980) Detrended correspondence analysis, an improved ordination technique. Vegetatio 42:47-58

Hogarth PJ, Gherardi F, McLaughlin PA (1998) Hermit crabs (Crustacea Decapoda Anomura) of the Maldives with the description of a new species of Catapagurus A. Milne Edwards 1880. Trop Zool 11:149-175

Imazu M, Asakura A (1994) Distribution, reproduction and shell utilisation patterns in three species of intertidal hermit crabs on a rocky shore on the Pacific coast of Japan. J Exp Mar Biol Ecol 184:41-65

Kellogg CW (1976) Gastropod shells: a potentially limiting resource for hermit crabs. J Exp Mar Biol Ecol 22:101-111

Kuris AM, Brody MS (1976) Use of principal components analysis to describe snail shell resource for hermit crabs. J Exp Mar Biol Ecol 22:69-77

Leite FPP, Turra A, Gandolfi SM (1998) Hermit crabs (Crustacea: Decapoda: Anomura), gastropod shells and environmental structure: their relationship in southeastern Brazil. J Nat Hist 32:1599-1608

Lewinsohn CH (1982) Researches on the coast of Somalia. The shore and the dune of Sar Uanle. 33. Diogenidae, Paguridae and Coenobitidae (Crustacea, Decapoda, Paguridea). Monit Zool Ital 2:35-68

Mars P, Salvat B, Thomassin B (1972) La faune malacologie littorale marine de Madagascar. In: Comptes rendus de la Conference internationale sur la conservation de la nature et de ses resources à Madagascar. Tananarive, 7-11 October 1970. Natural Sciences Supplementary Document 36. IUCN publication, Morges, p 209-211

McGuiness KA (1990) Physical variability, diversity gradients and the ecology of temperate and tropical reefs. Aust J Ecol 15:465-476

Editorial responsibility: Otto Kinne (Editor), Oldendorf/Luhe, Germany
Mileikovsky SA (1971) Types of larval development in marine bottom invertebrates, their distribution and ecological significance: a re-evaluation. Mar Biol 10:193-213

Niggerman R (1968) Zur Biologie und Ökologie des Landeinsiedlerkrebses Coenobita scaevola Forskal am Roten Meer. Oecologia 1:236-264

Nyblade CF (1974) Coexistence in sympatric hermit crabs. $\mathrm{PhD}$ thesis, University of Washington, Seattle

Orions GH, King CE (1964) Shell selection and invasion rates of some Pacific hermit crabs. Pac Sci 18:297-306

Pechenik JA, Lewis S (2000) Avoidance of drilled gastropod shells by the hermit crab Pagurus longicarpus at Nahant, Massachusetts. J Exp Mar Biol Ecol 253:17-32

Preston FW (1962) The canonical distribution of commonness and rarity. Ecology 43:185-215

Reay PJ, Haig J (1990) Coastal hermit crabs (Decapoda: Anomura) from Kenya, with a review and key to East African species. Bull Mar Sci 46:578-589

Reddy T, Bisewar R (1993) Patterns of shell utilization in two sympatric species of hermit crabs from the Natal coast (Decapoda, Anomura, Diogenidae). Crustaceana 65: $13-24$

Reese ES (1962) Shell selection behaviour of hermit crabs. Anim Behav 10:347-360

Reese ES (1969) Behavioural adaptations of intertidal hermit crabs. Am Zool 9:343-355

Rex MA, Stuart CT, Hessler RR, Allen JA, Sanders HL, Wilson GDF (1993) Global scale patterns of species diversity in the deep sea benthos. Nature 365:636-639

Roy K, Jablonski D, Valentine JW, Rosenberg G (1998) Marine latitudinal diversity gradients: tests of causal hypotheses. Proc Natl Acad Sci USA 95:3699-3702

Rutherford JD (1977) Removal of living snails from the shells by a hermit crab. Veliger 19:438-439

Samuelson TJ (1970) The biology of six species of Anomura (Crustacea, Decapoda) from Raunefjorden, western Norway. Sarsia 45:25-52

Scully EP (1979) The effects of gastropod shell availability and habitat characteristics on shell utilization by the intertidal hermit crab Pagurus longicarpus Say. J Exp Mar Biol Ecol 37:139-152

Siu BFC, Liu SY (1992) Shell preference and utilization pattern in two hermit crabs, Pagurus trigonocheirus (Stimpson) and Clibanarius bimaculatus (De Haan), on a sheltered rocky shore in Hong Kong. Asian Mar Biol 9: 205-216

Stehli FG, McAlester AL, Helsey CE (1967) Taxonomic diversity of recent bivalves and some implications for geology. Geol Soc Am Bull 78:455-466

Underwood AJ, Chapman MG (1996) Scales of spatial patterns of distribution of intertidal invertebrates. Oecologia 107:212-224

Underwood AJ, Chapman MG (1998) A method for analysing spatial scales of variation in composition of assemblages. Oecologia 117:570-578

Vance RR (1972) Competition and mechanisms of coexistence in three sympatric species of intertidal hermit crabs. Ecology 53:1062-1074

Vermeij GJ (1976) Interoceanic differences in vulnerability of shelled prey to crab predation. Nature 260:135-136

Wolda H (1981) Similarity indices, sample size and diversity. Oecologia 50:296-302

Young A (1979) Differential utilization of gastropod shells by three hermit crab species in North inlet, South Carolina, USA. Crustaceana 5:101-104

Submitted: January 8, 2002; Accepted: August 26, 2002

Proofs received from author(s): December 16, 2002 